\title{
Tax Neutrality: Illusion or Reality? The Case of Entrepreneurship
}

\author{
Vesa Kanniainen \\ University of Helsinki, CESifo and HECER \\ and \\ Paolo M. Panteghini \\ University of Brescia and CESifo
}

Discussion Paper No. 219

May 2008

ISSN 1795-0562

HECER - Helsinki Center of Economic Research, P.O. Box 17 (Arkadiankatu 7), FI-00014 University of Helsinki, FINLAND, Tel +358-9-191-28780, Fax +358-9-191-28781, E-mail info-hecer@helsinki.fi, Internet www.hecer.fi 


\title{
Tax Neutrality: Illusion or Reality? The Case of Entrepreneurship*
}

\begin{abstract}
This paper shows that taxes which are understood to be neutral with respect to the marginal investment decisions may be distortionary with respect to entrepreneurial decisions. In particular, we apply an intertemporal model to show that a comprehensive income tax is distortionary unless all kinds of income are subject to the same tax rate and a worker's option to become an entrepreneur is accounted for. Similarly, the harsh condition of a uniform tax rate is necessary but not sufficient under "new view" dividend tax, cash flow tax, and ACE tax, so that the occupational choice is not distorted. In any case, informational problems may arise and lead to distortive effects.
\end{abstract}

JEL Classification: H25.

Keywords: ACE tax; cash flow tax; dividend tax; Johansson-Samuelson theorem; real options.

Vesa Kanniainen

Department of Economics

University of Helsinki

P.O.Box 17

FI-00014 University of Helsinki

FINLAND

E-mail: vesa.kanniainen@helsinki.fi
Paolo M. Panteghini

Department of Economics

University of Brescia

Via San Faustino 74/b

IT-25122 Brescia

ITALY

E-mail: panteghi@eco.unibs.it

* The authors wish to thank Robert Chirinko and other participants of the 2008 CESifo Area Conference on Public Sector Economics, held in Munich, for their helpful comments. 


\section{Introduction}

For quite some time, the theoretical work on capital income taxation focused on under what conditions a tax system preserves investment neutrality. The idea of taxing corporate cash flow suggested by Brown (1948) and Smith (1963) was developed into a practical tax reform proposal by the Meade Committee (1978). It became understood that there are various ways of making the return on marginal investment tax-free. The notion of investment neutrality of dividend tax was subsequently introduced in the spirit of the socalled new view of equity finance and developed by various authors (Auerbach (1979), Bergström and Södersten (1977), Bradford (1981) and King (1977)). As in the case of cash flow tax, it was shown that dividend tax falls on the company value, not on the marginal investment returns. It turned out that such investment neutrality can be cast in a general condition, known as the Johansson-Samuelson Theorem (see Sinn (1987)): If all capital income is subject to a uniform marginal tax rate and if the tax depreciation coincides with true economic depreciation, the present value of the marginal cash flow is left unchanged by the imposition of the tax.

Echoing the ingenious tax theorem of Boadway and Bruce (1984), in 1991 the IFS Capital Taxes Group proposed the introduction of the Allowance for Corporate Equity (hereafter ACE), in UK corporate taxation. According to this proposal, the corporate tax base should be equal to the firm's current earnings net of: i) an arbitrary tax allowance for capital depreciation (not necessarily the cost of economic depreciation) and ii) the opportunity cost of finance. Moreover, it should ensure a symmetric treatment of profit and loss. According to the IFS proposal, the opportunity cost of finance should be equal to the default-free interest rate, thereby making the government "a sleeping partner in the risky project, sharing in the return, but also sharing some of the risk" (Devereux and Freeman, 1991, p.8). Under the ACE system the ordinary return, approximating the opportunity cost of new equity capital at the margin, is exempt at the corporate level: this leads to investment neutrality.

As witnessed by the US Report of the President's Advisory Panel on Tax Reform (2005), the debate on alternative tax options is intense. The Panel proposed two alternative tax schemes: the Simplified Income Tax (SIT) Plan, which is a comprehensive income tax, and the Growth and Investment Tax (GIT) Plan, which entails the taxation of cash flow at a business level, and also requires the taxation of dividends, capital gains and interest received 
(thus including normal income) at a personal level.

In this article, we claim that any of the above discussed tax formats though neutral around the steady state of a mature company - are distortionary in another important margin, i.e., at the stage of a start-up firm. ${ }^{1}$ As is well-known, the economics of a start-up firm is rather different from the economics of a mature company. What we show here is that neither of these discussed and celebrated tax systems can possibly be neutral at the stage of enterprise formation, unless the overall tax burden on entrepreneurial lifetime income is equal to the overall tax burden on labor income. Unfortunately, this is a special case that is unlikely to hold in any real tax system. Though our result can easily be proven, we think that it needs to be taken up to be delivered into the literature.

Our view is particularly valid in the context of an occupational model. We examine the issue further in the case where uncertainty makes it necessary also to consider timing, i.e., when the decision to start an entrepreneurial career is subject to an irreversible sunk cost. We then prove that, under a comprehensive income tax, the entrepreneurial choice is delayed unless the double taxation of income capital is eliminated and ad hoc depreciation allowances are ensured. We also demonstrate that uniform taxation is necessary even under cash-flow and ACE taxation in order for neutrality to hold. However, we will also show that these tax conditions are hard or even impossible to implement, because of informational problems.

The structure of this paper is as follows. Section 2 provides an insight to a simple model with no uncertainty. Section 3 introduces an intertemporal model which describes the effects of taxation on entrepreneurial choices by a representative agent when uncertainty shapes the value of the entrepreneurial career. Section 4 extends the model introduced in the previous section, by assuming that the representative entrepreneur has an option to quit the business sector and re-enter the labor market. Section 5 warns against simple policy implications from models of mature firms.

\footnotetext{
${ }^{1}$ The burden of dividend tax on initial equity injection and the growth path of a firm was examined by Sinn (1991). He did not, however, address the occupational choice issue which is our starting point.
} 


\section{The basic intuition}

The prevailing view of entrepreneurship builds on the occupational choice of heterogenous individuals, indexed by $i$. People are considered to take rational economic decisions on their career choices. The theoretical and empirical work has identified a number of differences characterizing these careers. The entrepreneurial career is subject to entry costs, risks, and to different tax principles when compared with workers who enter the labor market. Whatever these differences are, we denote the pre-tax value of the entrepreneurial career by $V$ (with potential options to optimize entry and exit) and the lifetime utility of a worker by $O$. We assume first that individuals make their career choices right at the start of the life-cycle with no option to delay. We assume moreover that people are homogenous as workers, but differ in terms of their entrepreneurial abilities, $a^{i}$. Then, by definition $\partial V\left(a^{i}\right) / \partial a^{i}>0$. If the total life-time tax liabilities from operating a firm as an entrepreneur, or alternatively, being a worker are denoted by $T$ and $T_{w}$, the entry condition under risk neutrality can be stated as

$$
V\left(a^{m}\right)-T=O-T_{w},
$$

where $a^{m}$ denotes the ability of the marginal entrepreneur. Individuals with $a^{i} \geq a^{m}$ choose entrepreneurship, individuals with $a^{i}<a^{m}$ become workers. Given (1), we can thus say that enterprise formation depends on total tax liabilities, rather than on marginal tax rates at various income levels. In particular, given the life-time tax liability of a worker, $T_{w}$, an increase in the tax liability on the entrepreneurial career affects the amount of start-up enterprises in the economy,

$$
\partial a^{m} / \partial T>0 .^{2}
$$

The non-neutrality result shown in (2) holds for any kind of tax on an entrepreneurial income, regardless of its potential neutrality with respect to income from the marginal capital on the growth path or around to the steady

\footnotetext{
${ }^{2}$ We notice that in a more complicated model it is not necessarily the case that an increase in the tax on entrepreneurship leads to fewer entrepreneurs. For example, it is well-known that the entrepreneurs can hide better their income than can workers from the tax authorities. With a higher tax rate, their incentive to do so might increase resulting in increased market entry as an entrepreneur.
} 
state. Tax neutrality for occupational choices holds only if the tax rates satisfy a particularly harsh requirement in terms of tax liabilities, $T=T_{w} \cdot{ }^{3}$

Therefore, even a comprehensive income tax is distortionary if the double taxation of capital income makes the total tax rate exceed tax on wage income. Under a comprehensive income tax without double taxation at a personal level, neutrality is carried over to the case of occupational choice, only on condition that the option values of the entrepreneur have been properly considered. As we will show, they must also include the option to quit the business activity.

Many entrepreneurial choices are dichotomous. In line with Devereux and Griffith (1999), therefore, whenever an agent faces a discrete choice between two or more mutually exclusive projects, it is the average rather than marginal effective tax rate which matters. Therefore, when the proponents of the "new view" of the dividend tax, the cash flow tax, the Johansson-Samuelson tax, or the ACE-tax claim to the neutrality of these taxes, they have in mind a different margin. This amounts to a situation where an established firm with some pre-invested capital is undertaking a marginal investment. While all those taxes are neutral with respect to the marginal investment decision, they typically distort the entrepreneurial entry decision. Even the JohanssonSamuelson tax distorts against the enterprise formation if the overall effective tax rate (arising typically in the case of double taxation) exceeds the total tax rate on labor income. We have been unable to locate this view in the literature. ${ }^{4}$

This means that, in terms of occupational choice, the effective average tax rate rather than the marginal one matters. This apparently innocuous result has crucial policy implications, in that it implies that many celebrated tax systems fail to be neutral in terms of entrepreneurship, unless harsher conditions are met. As we will see, however, many existing tax systems are distortive for the entrepreneurial choice, since they are characterized by progressive and/or double taxation.

\footnotetext{
${ }^{3}$ We interpret here the value of the entrepreneurial career to include any business options arising during the career.

${ }^{4}$ Neither did the Meade Committee (1978) discuss this case. The idea of neutrality of dividend tax has been challenged recently by Henreksson and Sanandaji (2004) and non-neutrality has been stated by Kanniainen, Kari and Ylä-Liedenpohja (2005, 2007), but otherwise it has been overlooked.
} 


\section{The intertemporal model}

In this section, we apply an intertemporal real-option model to study the effects of taxation on an individual's career choice. ${ }^{5}$ We consider an agent who first enters the labor market earning the market wage $w$ per unit of time. However, he has some business ideas that develop according to a stochastic process (to be introduced below). Once he is sufficiently convinced that the value of his business project exceeds some threshold level, he quits the labor market and establishes an own start-up firm. We first consider the case where the commitment to an entrepreneurial career is permanent. In the following section, we will analyze the case where the individual subsequently has an option to quit entrepreneurship and re-enter the labor market. The requirements for tax neutrality are then reconsidered in these cases.

For simplicity, we assume that the agents are risk-neutral ${ }^{6}$ and infinitelylived. ${ }^{7}$ Moreover, we introduce the following:

Assumption 1 at time $t=0$ the individual is a worker, earning an exogenous wage $w$, and is endowed with an option to start an entrepreneurial activity;

Assumption 2 to undertake a risky activity, the individual must pay a sunk start-up cost I;

Assumption 3 after entry, the firm's payoff at time $t$, defined as $\Pi_{t}$, is stochastic and moves according to the following process:

$$
\frac{d \Pi_{t}}{\Pi_{t}}=\alpha d t+\sigma d z_{t} \text { with } \Pi_{0}>0
$$

where $\alpha$ is the growth rate, $\sigma$ is the instantaneous standard deviation of $\frac{d \Pi_{t}}{\Pi_{t}}$, and $d z_{t}$ is a Wiener process.

Assumptions 1 to 3 deserve some comments. For simplicity the assumption 1 states that the pre-tax wage rate is exogenously given. As we let the

\footnotetext{
${ }^{5}$ The model here described draws on Panteghini's (2007a, Ch. 3) model.

${ }^{6}$ In doing so we will disregard the insurance effect played by taxation, extensively discussed by the relevant literature (after the pioneering article by Domar and Musgrave (1944)).

${ }^{7}$ This simplifying assumption does not affect the quality of results. For a discussion see, e.g., Panteghini (2007a).
} 
individual decide not only whether but also when to become an entrepreneur, this means that he is endowed with a call option. ${ }^{8}$

When the individual decides to become an entrepreneur, thus exercising the option, he loses his wage and, according to assumption 2, must pay $I$, which accounts for consultancy and administrative costs representing the strike price of the individual's option. It is worth noting that, whereas entry fees are observable, ${ }^{9}$ a relevant part of entry costs may be unobservable. As pointed out by Djankov et al. (2002) bureaucracy delays may be dramatic and therefore their cost may be high. ${ }^{10}$ Moreover, they may greatly vary from one individual to another, thereby causing heterogeneity, and preventing a precise measurement of entry costs.

According to assumption 3, the firm's payoff follows a stochastic process, described in (3) by a geometric Brownian motion. It is worth noting that the drift parameter $\alpha$ measures a worker's entrepreneurial ability: namely, the higher the parameter $\alpha$, the higher is the probability that our agent undertakes an entrepreneurial career successfully. ${ }^{11}$

Using these assumptions we calculate the pre-entry value function of the worker, defined as $O\left(\Pi_{t}\right)$, and the (post-entry) firm value, denoted by $V\left(\Pi_{t}\right)$. In particular, the pre-entry value function is equal to the current wage (namely, the wage received in the short interval $d t$ ) plus the remaining value, that is the value function after the instant $d t$ has passed. Defining $r$ as the relevant risk-free interest rate, and applying dynamic programming (see Panteghini, 2007a) we obtain: ${ }^{12}$

$$
O\left(\Pi_{t}\right)=w d t+e^{-r d t} \xi\left[O\left(\Pi_{t}+d \Pi_{t}\right)\right],
$$

where $\xi[$.$] is the expectation operator. Following the same procedure we can$ write the post-entry value function as

$$
V\left(\Pi_{t}\right)=\Pi_{t} d t+e^{-r d t} \xi\left[V\left(\Pi_{t}+d \Pi_{t}\right)\right] .
$$

\footnotetext{
${ }^{8}$ Since this option can be exercised at any future instant, it is an American call option. For further details, see McDonald and Siegel (1985, 1986).

${ }^{9}$ For a cross-country comparison of entry fees and procedures see World Bank's (2008) report Doing Business 2008.

${ }^{10}$ Djankov et al. (2002) also show that beaurocracy delays vary among countries.

${ }^{11}$ In line with section 2 , we could generalize our analysis by considering a set of potential entrepreneurs, each with his own $\alpha$, i.e., with his own entrepreneurial skills. However, the quality of results would not change.

${ }^{12}$ Under risk neutrality, the contingent claim analysis and dynamic programming lead to identical investment rules (Niemann and Sureth (2005)).
} 
Using (4) and (5) we can calculate the firm's trigger value $\Pi^{*}$, above which the entrepreneurial choice is profitable for an individual. For simplicity, hereafter we will omit the time variable.

\subsection{Comprehensive income taxation and the Johansson- Samuelson Theorem}

According to the well-known Schanz-Haig-Simons (hereafter, SHS) definition of income, the tax base must be comprehensive: in other words, it must include all income from production factors, such as labor, capital and nonreproducible factors (e.g., land, raw materials), net of expenses incurred in earning income. The idea underlying the SHS scheme is that the income tax base must be as close as possible to the true net income. Therefore, any change in the firm's net worth must be taken into account. Advocates of this tax argue not only that it is desirable in terms of fairness, but also that it is neutral for investment decisions. Indeed, according to the well-known Johansson-Samuelson Theorem (JST) ${ }^{13}$ if all kinds of capital are subject to the same marginal tax rate and fiscal depreciation allowances coincide with economic depreciation, then investment strategies are unaffected by taxation.

To analyze the effects of a SHS comprehensive income tax on entrepreneurship, let us denote $O^{J S}(\Pi)$ and $V^{J S}(\Pi)$ as the before- and after-entry value functions, respectively. Moreover, following the JST, the before-entry and after-entry depreciation allowance is equal to:

$$
\delta_{O} d t=-d O^{J S}(\Pi),
$$

and

$$
\delta_{V} d t=-d V^{J S}(\Pi),
$$

respectively. We can note that even with no physical depreciation, an individual's value function can change over time, because of the stochastic process (3). In particular, the value of a worker's option to enter the business sector appreciates if cash flow increases and depreciates if it decreases. Finally, we must remember that under a comprehensive income tax, all kinds of capital (including interest income) must be subject to taxation; therefore the relevant discount rate is $(1-\tau) r$. Defining $\tau_{w}$ and $\tau$ as the wage and business tax rate, respectively, we can thus prove that:

\footnotetext{
${ }^{13}$ The JST is the joint result of Johansson's $(1961,1969)$ and Samuelson's (1964) findings. For a discussion of the JST see e.g. Sinn (1987, Ch. 5).
} 
Proposition 1 Two conditions are needed for the entrepreneurial choice to be unaffected by taxation, first $\tau_{w}=\tau$, and second, a depreciation allowance has to coincide with the economic depreciation of the worker's option to become entrepreneur.

\section{Proof. See Appendix A.}

According to Proposition 1, uniform taxation is not sufficient to ensure entrepreneurial neutrality. In line with Niemann (1999), we have shown that neutrality holds in a real-option setting only if all sources of income, including changes in a taxpayer's portfolio of real option, are subject to taxation. This implies that a neutral income tax system also requires the deduction of economic depreciation related to the worker's entrepreneurial option. Otherwise, a distortion arises (see Alvarez and Kanniainen (1997)).

Proposition 1 has two important implications. First, it states that a uniform tax is necessary (but not sufficient) to ensure neutrality at the entry stage. This means that no double tax can be levied; otherwise, taxation discourages entrepreneurship. This result contradicts the new view of equity finance according to which a dividend tax is neutral. The intuition behind our result is simple: many well-known tax proposals (e.g., based on the new view) hold only for mature firms. We know, however, that most firms are not in a steady state but rather on their expansion or contraction paths, not to mention firms which are not yet created. For start-up and future firms, the neutrality of the dividend tax breaks down for the reasons discussed in the context of the comprehensive income tax and the JST.

A second implication regards information requirements. According to Proposition 1, a comprehensive income tax is neutral if a depreciation, i.e., $\delta_{O} d t=-d O^{J S}(\Pi)$, is allowed for workers. However, entrepreneurial ability, and thus the option value, varies from one worker to another. This means that due to the heterogeneity of workers, an informational problem arises. In the absence of market prices, it is fairly hard (or even impossible) to evaluate a worker's option, ${ }^{14}$ and therefore to measure his depreciation allowance. The problem arises from the existence of an information asymmetry where workers are the agents and the government is the principal. In such a context, an individual would be clearly induced to overstate his own entry option in order to reduce his before-entry tax burden.

\footnotetext{
${ }^{14}$ Notice that these option are not tradable.
} 


\subsection{Cash-flow and ACE taxation}

Let us next study two alternative consumption-based systems: a standard cash-flow tax and an ACE-type one. In both cases, interest income (i.e., normal income) is exempt, and therefore, the relevant discount rate is $r$.

Cash-flow tax Under cash-flow tax, the difference between receipts and outlays is taxed at, say the tax rate $\tau$ at any instant $t$. In this case, the after-tax cash flow will be equal to:

$$
\Pi^{C F}=(1-\tau) \Pi .
$$

Note that under cash-flow tax, the investment cost $I$ must be fully deducted when it is undertaken. The after-tax cost is therefore equal to $(1-\tau) I$.

ACE tax Under ACE tax, the entrepreneur's payoff, $\Pi$, is taxed at rate $\tau$, and, at any time period, a portion $\rho$ of the investment cost $I$ is deductible from current tax base where $\rho$ measures the cost of financing. ${ }^{15}$ Thus tax payments are equal to

$$
T(\Pi)=\tau(\Pi-\rho I) .
$$

Given (9), the firm's after-tax cash flow will then be

$$
\Pi^{A C E}=\Pi^{C F}+\tau \rho I .
$$

Using dynamic programming we can write an agent's before-entry value function as:

$$
O^{j}(\Pi)=\left(1-\tau_{w}\right) w d t+e^{-r d t} \xi\left[O^{j}(\Pi+d \Pi)\right] \text { with } j=C F, A C E .
$$

Solving (11) we obtain (see Appendix B):

$$
O^{j}(\Pi)=\frac{\left(1-\tau_{w}\right) w}{r}+A_{1}^{j} \Pi^{\beta_{1}}, \text { with } j=C F, A C E .
$$

\footnotetext{
${ }^{15}$ Boadway and Bruce (1984) assume that a representative firm is financed with both debt and equity. According to their tax system, the firm can deduct the total cost of capital, i.e., the market rate of interest, $r$, times the firm's capital, $K$, so that it can deduct $r K$ from the tax base. Here, we have assumed for simplicity that the firm is fully equity-financed. Thus, $\rho$ should be interpreted as the opportunity cost of equity. However, the quality of results would not change if we assumed an optimally-debt financed firm (see Panteghini, 2007b).
} 
As shown in (12), the worker's value function consists of two terms: the present value of after-tax wages, $\frac{\left(1-\tau_{w}\right) w}{r}$, and $A_{1}^{j} \Pi^{\beta_{1}}$, which measures his (call) option to enter the business sector. In particular, $A_{1}^{j}$ is an unknown to be determined and $\beta_{1}>1$.

Following the same procedure, we can write the after-entry value function as follows:

$$
V^{j}(\Pi)=\Pi^{j} d t+e^{-r d t} \xi\left[V^{j}(\Pi+d \Pi)\right] \text { with } j=C F, A C E .
$$

As shown in Appendix C, (13) can be solved as

$$
V^{j}(\Pi)=\left\{\begin{array}{ccc}
\frac{(1-\tau) \Pi}{r-\alpha} & \text { under } & C F, \\
\frac{(1-\tau) \Pi}{r-\alpha}+\frac{\rho}{r} \tau I & \text { under } & A C E .
\end{array}\right.
$$

It is worth noting that the relevant discount rate is given by the difference between the risk-free interest rate $r$ and the drift $\alpha$. By using the adjusted discount rate $(r-\alpha)$ we thus account for the expected increase in $\Pi$. As shown in (14), the individual's value function is a perpetual rent. This is due to the fact that, after entering the business sector, the individual is assumed not to make any further decisions.

Functions (12) and (14) allow us to deal with an individual's intertemporal decision. The individual's problem is one of choosing the optimal entrepreneurial timing, which can be associated with a trigger point $\Pi^{*, j}$. This means that, whenever the current income reaches $\Pi^{*, j}$, the individual starts his business activity. As shown in Appendix D, we obtain the trigger points under cash-flow and ACE tax, i.e.,

$$
\begin{gathered}
\Pi^{*, C F}=\frac{\beta_{1}}{\beta_{1}-1}(r-\alpha)\left[\frac{\left(1-\tau_{w}\right)}{(1-\tau)} \frac{w}{r}+I\right], \\
\Pi^{*, A C E}=\frac{\beta_{1}}{\beta_{1}-1}(r-\alpha)\left[\frac{\left(1-\tau_{w}\right)}{(1-\tau)} \frac{w}{r}+\frac{\left(1-\frac{\rho}{r} \tau\right)}{(1-\tau)} I\right],
\end{gathered}
$$

respectively. Using (12) and (14) we also find

$$
A_{1}^{j}=\frac{1}{\beta_{1}} \frac{(1-\tau)}{r-\alpha}\left(\Pi^{*, j}\right)^{1-\beta_{1}}>0, \text { with } j=C F, A C E .
$$

As can be seen in (15) and (16), the entrepreneur's trigger points $\Pi^{*, j}$ can be affected by tax rates $\tau_{w}$ and $\tau$. Given these results we can say that: 
Proposition 2 The timing decision of the entrepreneurial career is unaffected by taxation if:

1. under cash-flow taxation, $\tau_{w}=\tau$;

2. under ACE-type taxation, $\rho=r$, and $\tau_{w}=\tau$.

As shown by Proposition 2, uniform taxation is a necessary and sufficient neutrality condition under cash-flow taxation. In any case it implies that a firm's income cannot be taxed twice (i.e., both at the corporate level and at the personal level), otherwise, neutrality fails to hold. This result has an interesting policy implication: i.e., neutrality is ensured by a Hall-Rabushka flat tax (Hall and Rabushka (1995)) that entails the taxation of cash flow only at the firm level as well as uniform taxation. On the contrary, a distortion arises under the US Panel's GIT proposal, since this tax design entails a double taxation of capital income. ${ }^{16}$

Let us focus on the ACE proposal. In line with Devereux and Freeman (1991) and Bond and Devereux (1995), Proposition 2 states that neutrality can be achieved if $\rho=r$, i.e., if the tax treatment of the sunk cost $I$ is equivalent to that ensured by a cash-flow tax. ${ }^{17}$ However, Proposition 2 also requires that we must also have $\tau_{w}=\tau$. This means that an ACE-type tax is distortive in terms of start-up decisions, if business income is subject to double taxation. In particular, the lower the tax rate $\tau_{w}$ and/or the higher the tax rate $\tau$, the higher the trigger point $\Pi^{*}, A C E$ is. It is worth noting that double taxation was not excluded by the IFS Capital Taxes Group (1991). On this point, e.g., Devereux and Freeman (1991, p. 8) argued that the ACE can "operate in a classical relation with the personal tax system, so that, in administrative terms, it will function with any form of personal taxation". We can see that, however, entrepreneurship is discouraged if $\tau_{w}<\tau$.

Let us finally say, that under both systems, an implementation issue may arise because entry costs are partially unobservable. Like comprehensive

\footnotetext{
${ }^{16}$ Similarly, a distortion would also arise under Bradford's (1986) X tax. Under the Bradford proposal, indeed, labor income would be subject to a graduated-rate tax, and therefore, tax rates might differ from one taxpayer to another. This would violate the uniform-tax-rate condition.

${ }^{17}$ Brown $(1948$, p. 537) argues that distortions "can be substantially eliminated by a system which permits the firm to deduct either (1) current outlays (or an average of outlays for a short period) on depreciable assets or (2) normal depreciation on total assets". See Niemann (1999) and Panteghini (2001a, 2001b) for details on investment neutrality in a real-option framework.
} 
income taxation, an information asymmetry may arise, and therefore, cause a distortion for entry decisions.

\section{Entry and the option to quit}

Let us next analyze the impact of taxation on entrepreneurship when the individual also has an option to quit his business activity and re-enter the labor market. ${ }^{18}$ For simplicity, we assume that re-entering the labor market is an irreversible choice. We also introduce the following:

Assumption 4 If the individual re-enters the labor market he faces an exit cost equal to $E$.

Exit costs are at least partially unobservable. Indeed, parameter $E$ may account for on-the-job-search costs under unemployment. ${ }^{19}$ It is realistic to think that the higher the unemployment rate is, the higher the parameter $E$ is, and therefore the more costly it is to re-enter the labor market. ${ }^{20}$ Hence assumption 4 allows to deal with labor market flexibility; in other words, the higher the cost $E$, the less flexible the labor market is. As we will see, the effects of taxation may crucially depend on the characteristics of the labor market.

Exit costs also account for liquidation procedures, which are time-consuming, costly, and may vary from one case to another. ${ }^{21}$ Moreover, we must consider that our entrepreneur had already abandoned the labor market to undertake his business venture. Therefore, he may have lost employment protection, as well job benefits etc. In particular, health benefits financed by the employer are lost when the worker leaves. Yet, a worker might have paid the benefit in his wage which should in equilibrium capitalize such benefits. If not, loss of the benefits results in an exit cost which works against entrepreneurship. There may be other exit costs like the need to move to another location, the

\footnotetext{
${ }^{18}$ This implies that the entrepreneurial choice is now partially reversible. Since the individual faced a sunk cost when he entered the business sector, reversibility cannot be full.

${ }^{19}$ These costs may dramatically differ from an individual to another (see e.g. Card et al. (2007)).

${ }^{20}$ This is in line with Bruce (2002) who found that unemployment discourages exit.

${ }^{21}$ For a cross-country analysis of exit costs see World Bank's (2008) report Doing Business 2008.
} 
loss of co-workers as friends. As will be shown, the option to quit increases enterprise formation in the first place.

Given assumption 4, we can calculate the worker's post-exit value function as a perpetual rent, related to the wage rate $w$, net of $\operatorname{cost} E$, i.e., ${ }^{22}$

$$
W=\frac{w}{r}-E
$$

\subsection{Comprehensive income taxation}

We define $\phi$ as the percentage of deductibility of exit costs. Therefore, the worker's post-exit value function under income taxation will then be:

$$
W=\frac{\left(1-\tau_{w}\right) w}{(1-\tau) r}-\left(1-\phi \tau_{w}\right) E .
$$

As can be seen, (19) is given by a perpetual rent because, after re-entering the labor sector, an individual owns no option to change his status.

Given (19) we can prove the following:

Proposition 3 Three conditions are required for the entrepreneurial choices to be unaffected by income taxation: i) $\tau_{w}=\tau$, ii) $\phi=0$, and iii) a depreciation allowance coinciding with economic depreciation.

Proof. See Appendix E.

Proposition 3 represents a generalization of Proposition 1. As can be seen, no deduction is needed for the exit costs; it is indeed sufficient to set $\tau_{w}=\tau$ in order for exit to be undistorted by taxation. Given Propositions 1 and 3 we can say that implementation problems regarding income taxation are due to the impossibility of appropriately measuring the value of a worker's entry option. On the other hand, the tax treatment of exit does not cause any implementation problem per se.

\subsection{Cash-flow and ACE taxation}

Under cash-flow and ACE taxation, a worker's function has the following form:

\footnotetext{
${ }^{22}$ Since, by assumption, re-entering the labor market is an irreversible choice, the worker no longer has options, and therefore, $W$ is measured by a perpetual rent.
} 


$$
O^{j}(\Pi)=\frac{\left(1-\tau_{w}\right) w}{r}+B_{1}^{j} \Pi^{\beta_{1}} \text { with } j=C F, A C E .
$$

Notice that the option value $B_{1}^{j} \Pi^{\beta_{1}}$ differs from the term $A_{1}^{j} \Pi^{\beta_{1}}$ of function (12), in that it accounts for the higher degree of flexibility, namely the value of the (put) option to quit.

Since the entrepreneur can now decide to close his business activity and re-enter the labor market, the value function is

$$
V^{j}(\Pi)=\left\{\begin{array}{ccc}
\frac{(1-\tau) \Pi}{r-\alpha}+H_{2}^{C F} \Pi^{\beta_{2}} & \text { under } & C F, \\
\frac{(1-\tau) \Pi}{r-\alpha}+\frac{\rho}{r} \tau I+H_{2}^{A C E} \Pi^{\beta_{2}} & \text { under } & A C E .
\end{array}\right.
$$

If we compare (21) with (14), we have now the additional term $H_{2}^{j} \Pi^{\beta_{2}}$, which measures the individual' option to quit and to re-enter the labour market. Unlike the case analyzed in section 3 -where we applied the boundary condition $V^{j}(0)=0$ and thus set $H_{2}^{j}=0$-, in this case, the individual will find it optimal to quit for $V^{j}(\Pi)>0$. Since condition $V^{j}(0)=0$ does not hold, we now have $H_{2}^{T} \neq 0$.

Following the same procedure we can write the worker's value function after his exit from the business sector as:

$$
W(\Pi)=\frac{\left(1-\tau_{w}\right) w}{r}-\left(1-\phi \tau_{w}\right) E .
$$

Given (12), (21) and (22) we can now analyze an individual's decisions. Solutions are found backwards: we will first find the optimal exit point $\widetilde{\Pi}^{j}$ and then calculate the entry trigger point $\Pi^{* *, j}$, for $j=C F, A C E$. As shown in Appendix F, we obtain

$$
H_{2}^{j}=-\frac{1}{\beta_{2}} \frac{(1-\tau)}{r-\alpha}\left(\widetilde{\Pi}^{j}\right)^{1-\beta_{2}}>0
$$

and

$$
\widetilde{\Pi}^{j}=\left\{\begin{array}{ccc}
\frac{\beta_{2}}{\beta_{2}-1}(r-\alpha)\left[\frac{\left(1-\tau_{w}\right)}{(1-\tau)} \frac{(1-\phi) w}{r}-\frac{\left(1-\phi \tau_{w}\right)}{(1-\tau)} E\right] & \text { under } & C F, \\
\frac{\beta_{2}}{\beta_{2}-1}(r-\alpha)\left[\frac{\left(1-\tau_{w}\right)}{(1-\tau)} \frac{(1-\phi) w}{r}-\frac{\rho}{r} \tau I-\frac{\left(1-\phi \tau_{w}\right)}{(1-\tau)} E\right] & \text { under } & A C E .
\end{array}\right.
$$


Given $H_{2}^{j}>0$, we can calculate the entrepreneur's option to exit $H_{2}^{j} \Pi^{\beta_{2}}$. As can be seen, the trigger point $\widetilde{\Pi}^{j}$ is positively affected by the labor wage rate: i.e., the higher the wage, the higher the propensity to quit is. It is worth noting that $\widetilde{\Pi}^{C F}>\widetilde{\Pi}^{A C E}$. Under the ACE system indeed, the exit threshold point is reduced by the tax benefit $\frac{\rho}{r} \tau I$. Since such a benefit is lost whenever the individual decides to quit his business activity, he will be induced to delay the exit decision. Therefore, the higher the tax benefit $\tau \rho I$ is, the lower the point $\widetilde{\Pi}^{j}$ is, and the lower the probability of exit is.

In order to analyze the effects of taxation we use (24) and set $\tau_{w}=\tau=0$, thereby obtaining the zero-tax-rate trigger point:

$$
\widetilde{\Pi}_{L F}=\frac{\beta_{2}}{\beta_{2}-1}(r-\alpha)\left(\frac{w}{r}-E\right) .
$$

Using (24) and (25) we can say that:

Proposition 4 Under cash-flow taxation, the exit decision is unaffected by taxation, i.e., $\widetilde{\Pi}^{C F}=\widetilde{\Pi}_{L F}$ if $\tau_{w}=\tau$, and $\phi=1$. Under ACE taxation, even if $\rho=r, \tau_{w}=\tau$, and $\phi=1$, the inequality $\widetilde{\Pi}^{A C E}<\widetilde{\Pi}_{L F}$ holds.

According to Proposition 4, a uniform cash-flow tax is no longer neutral in terms of exit decisions unless exit costs are fully deductible. As we have pointed out, however, exit costs are at least partially unobservable; this means that, given information problems, the implementation of a neutral cash-flow tax is de facto impossible.

Under ACE taxation the above conditions are not sufficient. Comparing (24) with (25) we immediately see that $\widetilde{\Pi}^{A C E}=\widetilde{\Pi}_{L F}$, only if a rebate $R=\frac{\rho}{r} \tau I$ is granted. In particular, if we set $\rho=r$, the neutral rebate is $R=\tau I$, which coincides with the cash-flow tax benefit ensured by immediate write-off of $I .{ }^{23}$ Otherwise, the entrepreneur is induced to delay exit. ${ }^{24}$

\footnotetext{
${ }^{23}$ Notice that a distortion may also arise if losses are carried forward at the risk-free rate, but future positive revenues are not sufficient to use all tax credit (see Ball and Bowers (1983)).

${ }^{24}$ To our knowledge, among articles dealing with tax neutrality, only Panteghini (2006) has focused on exit. His article shows that, under default risk, a S-based system distorts the decision to default (that is, the exercise of the option to quit the business activity by existing shareholders).
} 
Let us next analyze the optimal entry decision. As shown in Appendix $\mathrm{G}$, the trigger point is equal to

$$
\Pi^{* *, j}=\left\{\begin{array}{c}
\frac{\beta_{1}}{\beta_{1}-1}(r-\alpha)\left[\frac{1-\tau_{w}}{1-\tau} \frac{w}{r}+I+\left(1-\frac{\beta_{2}}{\beta_{1}}\right) \frac{1}{\beta_{2}} \frac{1}{r-\alpha} \widetilde{\Pi}^{C F}\left(\frac{\widetilde{\Pi}^{C F}}{\Pi^{* * C F}}\right)^{-\beta_{2}}\right], \\
\frac{\beta_{1}}{\beta_{1}-1}(r-\alpha)\left[\frac{1-\tau_{w}}{1-\tau} \frac{w}{r}+\frac{1-\frac{\rho}{r} \tau}{1-\tau} I+\left(1-\frac{\beta_{2}}{\beta_{1}}\right) \frac{1}{\beta_{2}} \frac{1}{r-\alpha} \widetilde{\Pi}^{A C E}\left(\frac{\widetilde{\Pi}^{A C E}}{\Pi^{* *, A C E}}\right)^{-\beta_{2}}\right] .
\end{array}\right.
$$

Moreover we have

$$
B_{1}^{j}=\frac{\left(\Pi^{* *, j}\right)^{1-\beta_{1}}}{\beta_{1}}\left[\frac{(1-\tau)}{r-\alpha}+\beta_{2} H_{2}^{j}\left(\Pi^{* *, j}\right)^{\beta_{2}-1}\right] .
$$

Despite the fact that (26) is not a closed-form solution, we can compare $\Pi^{* *, j}$ with $\Pi^{*, j}$. Since the inequality

$$
\left(1-\frac{\beta_{2}}{\beta_{1}}\right) \frac{1}{\beta_{2}} \frac{1}{r-\alpha} \widetilde{\Pi}^{j}\left(\frac{\widetilde{\Pi}^{j}}{\Pi^{* *, j}}\right)^{-\beta_{2}}<0
$$

holds, the comparison of (15) and (16) with (26) allows to conclude that $\Pi^{*, j}>\Pi^{* *, j}$. This means that the exit option, that depends on labor market characteristic, affects entry decisions. The intuition behind this result is straightforward: the ability to exit ensures some degree of business flexibility. Given partial reversibility, therefore, the cost of undertaking the business activity is lower. This reduces the optimal threshold point.

The effect of partial reversibility on entry decisions can also be seen by comparing (17) with (27). Given inequality $\Pi^{*, j}>\Pi^{* *, j}$, we have $\left(\Pi^{*, j}\right)^{1-\beta_{1}}<$ $\left(\Pi^{* *, j}\right)^{1-\beta_{1}}$. Moreover the term $\beta_{2} H_{2}^{j}\left(\Pi^{* *, j}\right)^{\beta_{2}-1}$ is negative. It is therefore easy to state that $B_{1}^{j}<A_{1}^{j}$. In other words, the existence of the option to quit makes the worker's option to start less valuable. This lower value may explain why the option is exercised earlier, i.e., $\Pi^{*, j}>\Pi^{* *, j}$.

Given (26), we can show that:

Proposition 5 The entry decision is unaffected by either cash-flow or ACE taxation only if exit is undistorted.

As shown in (26), entry is affected by exit. According to Proposition 5 , therefore, full neutrality is ensured only if quite restrictive conditions are introduced; in particular, the full deduction of exit costs is necessary. As we have pointed out, however, it is almost impossible to measure all these costs. This implies that, due to informational problems, a neutral cash-flow or ACE tax is de facto not implementable. 


\section{Concluding remarks}

Our paper has highlighted that the idea of income tax neutrality is more often an illusion than reality. It has produced results which carry a frustrating message for tax economists not to mention policy-makers. This paper has shown that a number of well-known neutral systems of taxing income from existing corporations with little expansion prospects typically distorts the economic decisions both at the start-up and at the liquidation stage. In our view, the trouble with previous tax analyses has been that they have been based on overly simplified models focusing on long-term equilibrium. Enterprises however, typically have a life-cycle. No enterprise can be created as a mature company. Each enterprise has a beginning and may have a death. Furthermore, given the high heterogeneity of (observable) entry and exit costs among countries (see World Bank (2008)), we can say that the implementation of a given tax system may have an impact that dramatically differs from one country to another. It is not of secondary importance to understand in what way is the life cycle of enterprises affected by business and labor taxation. 


\section{A Proof of Proposition 1}

Given the before-entry depreciation allowance $\delta_{O}$, a worker's tax base is equal $\mathrm{to}^{25}$

$$
B=w-\delta_{O}
$$

Using (28) and applying dynamic programming, we can write the worker's value function as:

$$
O^{J S}(\Pi)=\left[\left(1-\tau_{w}\right) w+\tau_{w} \delta_{O}\right] w d t+e^{-(1-\tau) r d t} \xi\left[O^{J S}(\Pi+d \Pi)\right] .
$$

Expanding the RHS of (29) and applying Itô's Lemma gives:

$$
\begin{aligned}
& O^{J S}(\Pi)=\left[\left(1-\tau_{w}\right) w+\tau_{w} \delta_{O}\right] d t \\
& +[1-(1-\tau) r d t]\left[O^{J S}(\Pi)+d O^{J S}(\Pi)\right]+o(d t),
\end{aligned}
$$

where $o(d t)$ is the summation of all terms that go to zero faster than $d t$, and

$$
d O^{J S}(\Pi)=\left[\alpha \Pi O_{\Pi}^{J S}+\frac{\sigma^{2}}{2} \Pi^{2} O_{\Pi \Pi}^{J S}\right] d t,
$$

with $O_{\Pi}^{J S}=\frac{\partial O^{J S}(\Pi)}{\partial \Pi}$, and $O_{\Pi \Pi}^{J S}=\frac{\partial^{2} O^{J S}(\Pi)}{\partial \Pi^{2}}$. Substituting (31) into (30) gives

$$
\begin{gathered}
O^{J S}(\Pi)=\left[\left(1-\tau_{w}\right) w+\tau_{w} \delta_{O}\right] d t+(1-(1-\tau) r d t) O^{J S}(\Pi) \\
+\left[\alpha \Pi O_{\Pi}^{J S}+\frac{\sigma^{2}}{2} \Pi^{2} O_{\Pi \Pi}^{J S}\right] d t .
\end{gathered}
$$

Following Samuelson (1964), and using (6) we have

$$
\delta_{O} d t=-d O^{J S}(\Pi)=-\left[\alpha \Pi O_{\Pi}^{J S}+\frac{\sigma^{2}}{2} \Pi^{2} O_{\Pi \Pi}^{J S}\right] d t .
$$

Using (31) and rearranging (32) gives

$$
(1-\tau) r O^{J S}(\Pi)=\left(1-\tau_{w}\right) w+\left(1-\tau_{w}\right)\left[\alpha \Pi O_{\Pi}^{J S}+\frac{\sigma^{2}}{2} \Pi^{2} O_{\Pi \Pi}^{J S}\right] .
$$

If $\tau=\tau_{w}$, the non-arbitrage condition (33) reduces to

$$
r O^{J S}(\Pi)=w+\alpha \Pi O_{\Pi}^{J S}+\frac{\sigma^{2}}{2} \Pi^{2} O_{\Pi \Pi}^{J S} .
$$

\footnotetext{
${ }^{25}$ The depreciation or appreciation refers to a worker's productivity or skill as an entrepreneur.
} 
Let us next turn to the firm's value function. Under a comprehensive income tax system, the firm's tax base is equal to

$$
\Pi^{J S}=\Pi-\delta_{V}
$$

Using (35) and applying dynamic programming we can write the firm's project value as:

$$
V^{J S}(\Pi)=\left[(1-\tau) \Pi+\tau \delta_{V}\right] d t+e^{-r d t} \xi\left[V^{J S}(\Pi+d \Pi)\right] .
$$

Expanding the RHS of (36), and applying Itô's Lemma gives the following differential equation

$$
\begin{aligned}
V^{J S}(\Pi)=[ & \left.(1-\tau) \Pi+\tau \delta_{V}\right] d t+(1-(1-\tau) r d t) V^{J S}(\Pi) \\
& +\left[\alpha \Pi V_{\Pi}^{J S}+\frac{\sigma^{2}}{2} \Pi^{2} V_{\Pi \Pi}^{J S}\right] d t+o(d t)
\end{aligned}
$$

where $V_{\Pi}^{J S}=\frac{\partial V^{J S}(\Pi)}{\partial \Pi}, V_{\Pi \Pi}^{J S}=\frac{\partial^{2} V^{J S}(\Pi)}{\partial \Pi^{2}}$. Using (7) we have

$$
\delta_{V} d t=-d V^{J S}(\Pi)=\left[\alpha \Pi V_{\Pi}^{J S}+\frac{\sigma^{2}}{2} \Pi^{2} V_{\Pi \Pi}^{J S}\right] d t .
$$

Rearranging (37) gives

$$
r V^{J S}(\Pi)=\Pi+\alpha \Pi V_{\Pi}^{J S}+\frac{\sigma^{2}}{2} \Pi^{2} V_{\Pi \Pi}^{J S} .
$$

Using (34) and (38) we can show that the non-arbitrage condition of the entrepreneurial project, net of the option, i.e.,

$$
r\left[V^{J S}(\Pi)-O^{J S}(\Pi)\right]=(\Pi-w)+\alpha \Pi\left(V_{\Pi}^{J S}-O_{\Pi}^{J S}\right)+\frac{\sigma^{2}}{2} \Pi^{2}\left(V_{\Pi \Pi}^{J S}-O_{\Pi \Pi}^{J S}\right),
$$

is unaffected by taxation. This means that the entrepreneurial decision is undistorted by a uniform-rate comprehensive income tax.

\section{B The calculation of (12)}

Let us expand the RHS of (11) and apply Itô's Lemma to obtain

$$
O^{j}(\Pi)=\left(1-\tau_{w}\right) w d t+(1-r d t)\left[O^{j}(\Pi)+d O^{j}(\Pi)\right]+o(d t)
$$


where

$$
d O^{j}(\Pi)=\left[\alpha \Pi O_{\Pi}^{j}+\frac{\sigma^{2}}{2} \Pi^{2} O_{\Pi \Pi}^{j}\right] d t
$$

with $O_{\Pi}^{j}=\frac{\partial O^{j}(\Pi)}{\partial \Pi}$ and $O_{\Pi \Pi}^{j}=\frac{\partial^{2} O^{j}(\Pi)}{\partial \Pi^{2}}$. Substituting (40) into (39) gives

$$
O^{j}(\Pi)=\left(1-\tau_{w}\right) w d t+(1-r d t) O^{j}(\Pi)+\left[\alpha \Pi O_{\Pi}^{j}+\frac{\sigma^{2}}{2} \Pi^{2} O_{\Pi \Pi}^{j}\right] d t .
$$

Simplifying (41) gives

$$
r O(\Pi)=\left(1-\tau_{w}\right) w+\alpha \Pi O_{\Pi}^{j}+\frac{\sigma^{2}}{2} \Pi^{2} O_{\Pi \Pi}^{j} \cdot
$$

As shown by Dixit and Pindyck (1994), equation (42) has the following general closed-form solution

$$
O^{j}(\Pi)=A_{0}+\sum_{i=1}^{2} A_{i}^{j} \Pi^{\beta_{i}(\lambda)} .
$$

Substituting (43) into (42) and solving gives

$$
A_{0}=\frac{\left(1-\tau_{w}\right) w}{r}
$$

and the quadratic equation

$$
\Psi\left(\beta_{i}\right) \equiv \frac{\sigma^{2}}{2} \beta_{i}\left(\beta_{i}-1\right)+\alpha \beta_{i}-r=0 .
$$

Eq. (44) is usually known as the characteristic equation and has the following two roots:

$$
\beta_{1}=\frac{1}{2}-\frac{\alpha}{\sigma^{2}}+\sqrt{\left(\frac{\alpha}{\sigma^{2}}-\frac{1}{2}\right)^{2}+\frac{2 r}{\sigma^{2}}}>1,
$$

and

$$
\beta_{2}=\frac{1}{2}-\frac{\alpha}{\sigma^{2}}-\sqrt{\left(\frac{\alpha}{\sigma^{2}}-\frac{1}{2}\right)^{2}+\frac{2 r}{\sigma^{2}}}<0 .
$$

Given these results, we can next calculate $A_{2}^{j}$. It is worth noting that when $\Pi$ goes to zero it will remain zero in the geometric Brownian motion. ${ }^{26}$ This

\footnotetext{
${ }^{26}$ Dixit and Pindyck (1994, Ch. 5) provide further details on this point.
} 
means that $\Pi=0$ is an absorbing barrier, and, therefore, a worker's value function reduces to

$$
O(0)=\frac{\left(1-\tau_{w}\right) w}{r} .
$$

Notice that, given $\beta_{2}<0$, if ab absurdo $A_{2}^{j} \neq 0$, we would have

$$
\lim _{\Pi \rightarrow 0} A_{2}^{j} \Pi^{\beta_{2}}=\infty,
$$

and the condition (45) would fail to hold. This implies that we must set $A_{2}=0$. Equation (12) is thus obtained.

\section{The calculation of (14)}

Let us expand the RHS of (13) and apply Itô's Lemma to obtain

$$
V^{j}(\Pi)=\Pi^{j} d t+(1-r d t) V^{j}(\Pi)+\left[\alpha \Pi V_{\Pi}^{j}+\frac{\sigma^{2}}{2} \Pi^{2} V_{\Pi \Pi}^{j}\right] d t+o(d t)
$$

where $V_{\Pi}^{j}=\frac{\partial V^{j}(\Pi)}{\partial \Pi}$ and $V_{\Pi \Pi}^{j}=\frac{\partial^{2} V^{j}(\Pi)}{\partial \Pi^{2}}$. Simplifying (46) gives

$$
r V^{j}(\Pi)=\Pi^{j}+\alpha \Pi V_{\Pi}+\frac{\sigma^{2}}{2} \Pi^{2} V_{\Pi \Pi} .
$$

The solution of (47) has the following structure:

$$
V^{j}(\Pi)=\left\{\begin{array}{ccc}
\frac{(1-\tau) \Pi}{r-\alpha}+\sum_{j=1}^{2} H_{i}^{C F} \Pi^{\beta_{i}} & \text { under } & C F, \\
\frac{(1-\tau) \Pi}{r-\alpha}+\frac{\rho}{r} \tau I+\sum_{j=1}^{2} H_{i}^{A C E} \Pi^{\beta_{i}} & \text { under } & A C E,
\end{array}\right.
$$

Let us next calculate $H_{i}^{j}$ for $i=1,2$. As regards $H_{2}^{j}$, we know that $\Pi=0$ is an absorbing barrier and that the condition $V^{j}(0)=0$ holds. This implies that $H_{2}^{j}=0$. To calculate $H_{1}^{j}$ we recall Dixit and Pindyck's (1994) explanation according to which the term $H_{1}^{j} \Pi^{\beta_{1}(\lambda)}$ may be referred to speculative bubbles. In the absence of bubble, we have therefore $H_{1}^{i}=0$. We have thus obtained (14). 


\section{The optimal entry timing}

To find the optimal trigger point, $\Pi^{*, j}$, above which entry is profitable we apply the Value Matching Condition (VMC) and the Smooth Pasting Condition (SPC). The VMC requires the equality between the present value of the project, net of the investment cost, and the value of the option to delay investment, at point $\Pi=\Pi^{*, j}$, namely:

$$
V^{j}\left(\Pi^{*, j}\right)-I=O^{j}\left(\Pi^{*, j}\right) \text { with } j=C F, A C E .
$$

The VMC (48) implies that when the option is exercised optimally (i.e., at point $\left.\Pi=\Pi^{*, j}\right)$ the entrepreneur receives a net payoff equal to $V\left(\Pi^{*, j}\right)-I$.

The SPC requires the equality between the slopes of $\left[V^{j}(\Pi)-I\right]$ and $O^{j}(\Pi)$ at point $\Pi=\Pi^{*, j}$, i.e.,

$$
\left.\frac{\partial\left[V^{j}(\Pi)-I\right]}{\partial \Pi}\right|_{\Pi=\Pi^{*, j}}=\left.\frac{\partial O^{j}(\Pi)}{\partial \Pi}\right|_{\Pi=\Pi^{*, j}} .
$$

The SPC (49) equates the marginal benefit of entrepreneurship (on the LHS) and the marginal cost of exercising the option (on the RHS), that is the marginal cost of losing business flexibility. Substituting (12) and (14) into (48) and (49) and solving gives (16) and (17).

\section{E Proof of Proposition 3}

As shown by Proposition 1, neutrality in terms of entry holds only if $\tau_{w}=\tau$, and economic depreciation of the worker's option to become entrepreneur is deductible. To prove neutrality in terms of exit, it is thus sufficient to show that the same rule must hold for the after-exit value function.

Under an income tax, the after-exit net present value is equal to

$$
W^{J S}(\Pi)=\frac{\left(1-\tau_{w}\right) w}{(1-\tau) r}-\left(1-\phi \tau_{w}\right) E .
$$

By setting $\tau=\tau_{w}$ and $\phi=0,(50)$ collapses to (18). Given this result and Proposition 1, we can thus say that the joint application of uniform taxation and economic depreciation ensures tax-rate invariance. This concludes the proof of Proposition 3. 


\section{F Optimal exit timing under consumption- based taxation}

To find the optimal exit point, we substitute (21) and (22) into (48) and (49). Under cash-flow taxation we have

$$
\frac{(1-\tau) \widetilde{\Pi}^{C F}}{r-\alpha}+H_{2}^{C F}\left(\widetilde{\Pi}^{C F}\right)^{\beta_{2}}=\frac{\left(1-\tau_{w}\right) w}{r}-\left(1-\phi \tau_{w}\right) E,
$$

and

$$
\frac{(1-\tau)}{r-\alpha}+\beta_{2} H_{2}^{C F}\left(\widetilde{\Pi}^{C F}\right)^{\beta_{2}-1}=0
$$

Under ACE taxation we have the following two-equation system:

$$
\begin{gathered}
\frac{(1-\tau) \widetilde{\Pi}^{A C E}}{r-\alpha}+\frac{\rho}{r} \tau I+H_{2}^{A C E}\left(\widetilde{\Pi}^{A C E}\right)^{\beta_{2}}=\frac{\left(1-\tau_{w}\right) w}{r}-\left(1-\phi \tau_{w}\right) E \\
\frac{(1-\tau)}{r-\alpha}+\beta_{2} H_{2}^{A C E}\left(\widetilde{\Pi}^{A C E}\right)^{\beta_{2}-1}=0
\end{gathered}
$$

Solving the systems (51)-(52), and (53)-(54) for $H_{2}^{j}$ and $\widetilde{\Pi}^{j}$, with $j=C F, A C E$, gives (23) and (24), respectively.

\section{G Optimal start-up timing with the option to quit}

The optimal start-up timing is obtained by substituting (20) and (21) into (48) and (49). Under cash-flow taxation, we have:

$$
\frac{(1-\tau) \Pi^{* *, C F}}{r-\alpha}+H_{2}^{C F} \Pi^{* *, C F^{\beta_{2}}}-I=\frac{\left(1-\tau_{w}\right) w}{r}+B_{1}^{C F} \Pi^{* *, C F^{\beta_{1}}},
$$

and

$$
\frac{(1-\tau)}{r-\alpha}+\beta_{2} H_{2}^{C F} \Pi^{* *, C F^{\beta_{2}-1}}=\beta_{1} B_{1}^{C F} \Pi^{* *, C F^{\beta_{1}-1}} .
$$

Similarly, under the ACE system we have

$$
\frac{(1-\tau) \Pi^{* *, A C E}}{r-\alpha}+\frac{\rho}{r} \tau I+H_{2}^{A C E} \Pi^{* *, A C E^{\beta_{2}}}-I=\frac{\left(1-\tau_{w}\right) w}{r}+B_{1}^{A C E} \Pi^{* *, A C E^{\beta_{1}}},
$$




$$
\frac{(1-\tau)}{r-\alpha}+\beta_{2} H_{2}^{A C E} \Pi^{* *, A C E^{\beta_{2}-1}}=\beta_{1} B_{1}^{A C E} \Pi^{* *, A C E^{\beta_{1}-1}} .
$$

Next solve (55) and (56) for $\Pi^{* *, C F}$ and $B_{1}^{C F}$. Similarly, solve (57) and (58) for $\Pi^{* *, A C E}$ and $B_{1}^{A C E}$. We thus obtain (26) and (27). 


\section{References}

[1] Alvarez L. and V. Kanniainen (1997), Valuation of Irreversible Entry Options under Uncertainty and Taxation, CES Working Paper No. 144.

[2] Auerbach A.J. (1979), Wealth Maximization and the Cost of Capital, Quarterly Journal of Economics, 93, pp. 433-466.

[3] Ball R. and J. Bowers (1983), Distortions Created by Taxes which are Options on Value Creation: The Australian Resources Rent Tax Proposal, Australian Journal of Management, 8, pp. 1-14.

[4] Bergström V. and J. Södersten (1977), Double Taxation and Corporate Capital Costs, a paper presented at the Econometric Society Meeting, Vienna 1977.

[5] Boadway R. and N. Bruce (1984), A General Proposition on the Design of a Neutral Business Tax, Journal of Public Economics, 24, pp. 231-239.

[6] Bond S.R. and M.P. Devereux (1995), On the Design of a Neutral Business Tax under Uncertainty, Journal of Public Economics, 58, pp. 57-71.

[7] Bradford D.F. (1981), The Incidence and Allocation Effects of a Tax on Corporate Distributions, Journal of Public Economics, 15, pp. 1-22.

[8] Bradford D.F. (1986), Untangling the Income Tax, Cambridge, MA, and London: Harvard University Press.

[9] Brown E.C. (1948), Business-Income Taxation and Investment Incentives, in L.A. Meltzer, E.D. Domar et al. (eds.), Income, Employment and Public Policy, Essays in Honor of A.H. Hansen, New York: W.W. Norton \& c.

[10] Bruce D. (2002), Taxes and Entrepreneurial Endurance: Evidence from the Self-Employed, National Tax Journal, 55, pp. 5-24.

[11] Card D., R. Chetty and A. Weber (2007), Cash-on-Hand and Competing Models of Intertemporal Behavior: New Evidence from the Labor Market, Quarterly Journal of Economics, 122, pp. 1511-1560.

[12] Devereux M.P. and H. Freeman (1991), A General Neutral Profits Tax, Fiscal Studies, 12, pp. 1-15. 
[13] Devereux M.P. and R. Griffith (1999), The Taxation of Discrete Investment Choices, IFS Working Paper Series No. W98/16.

[14] Dixit A. and R.S. Pindyck (1994), Investment under Uncertainty, Princeton University Press, Princeton.

[15] Djankov S., R. La Porta, F. Lopez-de-Silanes and A. Shleifer (2002), The Regulation of Entry, Quarterly Journal of Economics, 117, pp. 1-37.

[16] Domar E.D. and R.A. Musgrave (1944), Proportional Income Taxation and Risk-taking, Quarterly Journal of Economics, 58, pp. 388-422.

[17] Hall R.E. and A. Rabushka (1995), The Flat Tax, Stanford: Hoover Institution Press.

[18] Henrekson M. and T. Sanandaji (2004), Ägarbeskanningen och företagandet, Stockholm: SNS Förlag.

[19] IFS Capital Taxes Group (1991), Equity for Companies: A Corporation Tax for the 1990s, A Report of the IFS Capital Taxes Group chaired by M. Gammie, The Institute for Fiscal Studies, Commentary 26, London.

[20] Johansson S.-E. (1961), Skatt-Investering-Värdering, Stockholm.

[21] Johansson S.-E. (1969), Income Taxes and Investment Decisions, Swedish Journal of Economics, 71, pp. 104-110.

[22] Kanniainen V., S.J. Kari and J. Ylä-Liedenpohja (2005), The StartUp and Growth Stages in Enterprise Formation: The 'New View' of Dividend Taxation Reconsidered, CESifo Working Paper No. 1476.

[23] Kanniainen V., S.J. Kari and J. Ylä-Liedenpohja (2007), Nordic Dual Income Taxation of Entrepreneurs, International Tax and Public Finance, 14, pp. 407-426.

[24] King M. (1977), Public Policy and the Corporation, London: Chapman and Hall.

[25] McDonald R. and D. Siegel (1985), Investment and the Valuation of Firms When There is an Option to Shut Down, International Economic Review, 26, pp. 331-349. 
[26] McDonald R. and D. Siegel (1986), The Value of Waiting to Invest, Quarterly Journal of Economics, 101, pp. 707-728.

[27] Meade Committee (1978), The Structure and Reform of Direct Taxation, London: George Allen and Unwin.

[28] Niemann R. (1999), Neutral Taxation under Uncertainty - A Real Option Approach, Finanzarchiv, 56, pp. 51-66.

[29] Niemann R. and C. Sureth (2005), Capital Budgeting with Taxes under Uncertainty and Irreversibility, Jahrbucher fur Nationalokonomie und Statistik, 225, pp. 77-95.

[30] Panteghini P.M. (2001a), On Corporate Tax Asymmetries and Neutrality, German Economic Review, 2, pp. 269-286.

[31] Panteghini P.M. (2001b), Corporate Tax Asymmetries under Investment Irreversibility, Finanzarchiv, 58, pp. 207-226.

[32] Panteghini P.M. (2006), S-Based Taxation under Default Risk, Journal of Public Economics, 90, pp. 1923-1937.

[33] Panteghini P.M. (2007a), Corporate Taxation in a Dynamic World, Berlin: Springer.

[34] Panteghini P.M. (2007b), Interest Deductibility under Default Risk and the Unfavorable Tax Treatment of Investment Costs: A Simple Explanation, Economics Letters, 96, pp. 1-7.

[35] President's Advisory Panel on Tax Reform (2005), Simple, Fair, and Pro-Growth: Proposals to Fix America's Tax System, Washington D.C.

[36] Samuelson P.A. (1964), Tax Deductibility of Economic Depreciation to Insure Invariant Valuations, Journal of Political Economy, 72, pp. 604606.

[37] Sinn H.W. (1987), Capital Income Taxation and Resource Allocation, Amsterdam: North-Holland.

[38] Sinn H.W. (1991), The Vanishing Harberger Triangle, Journal of Public Economics, 45, pp. 271-300. 
[39] Smith V. (1963), Tax Depreciation Policy and Investment Theory, International Economic Review, 4, pp. 80-91.

[40] World Bank (2008), Doing Business 2008, Washington D.C. 